\title{
Aplikasi Pulse Neutron Logging untuk Menentukan Zona Hidrokarbon Baru di Lapangan X
}

\author{
Eko Prastio, ST, MT*1 \\ 1Teknik Perminyakan, Fakultas Teknik, UBJ, Jakarta, Indonesia \\ email: *1eko.prastio@dsn.ubharajaya.ac.id
}

\begin{abstract}
Neutron Porosity measurement on open wells (Open Hole) is intended to measure the hydrogen index contained in rock formations. The hydrogen index is defined as the ratio of the concentration of hydrogen atoms per $\mathrm{cm}^{3}$ of rock to the content of pure water at $75 \mathrm{~F}$. Neutron Porosity log does not measure the true porosity of rocks, but what is measured is the hydrogen content found in the pores of rocks. Simply put, the more porous the rock the more hydrogen content and the higher the hydrogen index. Thus, shale which contains a lot of hydrogen can be interpreted to have a high porosity as well. To anticipate this uncertainty, in practice, interpretation of porosity can be done by elaborating log density logging. The above measurements are carried out on an open well (Open Hole) to determine the response of lithology, salinity, fluid type and others. Meanwhile, measuring Neutrons in closed wells (Cased Holes) will be difficult and requires special tools.
\end{abstract}

Keywords: Pulse Neutron Log, tubing, Hydrogen Index

\section{PENDAHULUAN}

Pengukuran Neutron Porosity pada evaluasi formasi ditujukan untuk mengukur indeks hydrogen yang terdapat pada formasi batuan. Indeks hydrogen didefinsikan sebagai rasio dari konsentrasi atom hydrogen setiap $\mathrm{cm}$ kubik batuan terhadap kandungan air murni. Neutron Porosity log tidaklah mengukur porositas sesungguhnya dari batuan, melainkan yang diukur adalah kandungan hydrogen yang terdapat pada pori-pori batuan (Harsono, 2006). Secara sederhana, semakin berpori batuan semakin banyak kandungan hydrogen dan semakin tinggi indeks hydrogen. Sehingga, shale yang banyak mengandung hydrogen dapat ditafsirkan memiliki porositas yang tinggi pula.

Log Neutron digunakan untuk membedakan formasi yang porous dan mendeterminasi porositasnya. Log ini mendeteksi keberadaan hidrogen di dalam formasi. Pada formasi bersih pori - pori telah terisi oleh air atau minyak, log neutron merefleksikan porositas yang terisi oleh fluida.Neutron merupakan bagian dari atom yang tidak memiliki muatan namun massanya ekuivalen dengan inti hydrogen (Harsono, 2006)

Neutron berinteraksi dengan material lain melalui dua cara, yaitu melalui kolisi dan absorbsi. Kolisi umumnya terjadi pada tingkat energi tinggi dan absorbsi terjadi pada tingkat energi yang lebih rendah. Jumlah energi yang hilang setiap kali terjadi kolisi tergantung pada massa relatif inti yang betumbukan dengan neutron tersebut (De Coaster, 2005)

Tumbukan dengan inti yang berat tidak akan terlalu memperlambat laju dari neutron. Jadi, penurunan terbesar jumlah neutron yang kembali ditentukan oleh seberapa besar kandungan air di dalam formasi batuan tersebut. Dalam waktu beberapa mikrodetik, neutron yang telah diperlambat melalui kolisi akan bergerak menyebar secara acak tanpa kehilangan banyak energi. Neutron tersebut baru akan berhenti apabila ditangkap oleh inti dari atom seperti klorin, hidrogen, atau silikon. 


\section{METODE PENELITIAN Pengumpulan Data}

Pengumpulan data kali ini dapat berasal dari lapangan. Data tersebut berupa data LAS, NTI, Open Hole Log, Cased Hole Log, Well Diagram dan beberapa file histori dari sumur tersebut (Eko, 2010)

\section{Pengolahan Data}

Depth Match adalah menyelaraskan atau menyamakan data GR open Hole dengan data GR Cased Hole. Kemudian dilanjutkan dengan kalibrasi dari setiap Pass. Kalibrasi bertujuan agar data yang telah kita dapat terkoreksi dengan lingkungan sumur Pada proses berikutny yaitu Gain Stabilization, dengan ini semua kurva akan diselaraskan pada Hydrogen Peak Window. Tahap berikutnya yaitu Pulse Neutron Interpretation, pada proses ini akan memasukan beberapa data yang di butuh kan ke dalam sistem seperti data Vshale, RhoOil, RhoGas, Litology, Bit Size, TPor dan Lainlain. Biasanya data tersebut bisa kita dapat melalui data Open Hole (Eko, 2010)

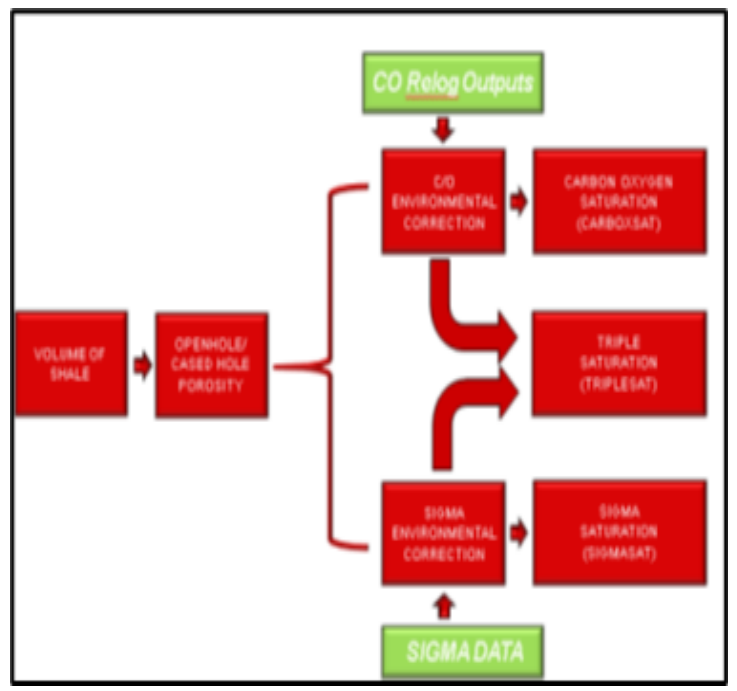

Gambar 1 Flow Diagram proses PNL

Pada Flow Chart di atas kita dapat melihat alur kerja dalam pemrosesan data PNL ini. Pada proses akhir kita dapat melihat tiga

kolom yaitu Carboxsat Log, Sigmasat Log dan Triplesat Log. Untuk Carboxsat Log di peruntukan untuk mencari saturasi Minyak. Sigmasat Log untuk mencari saturasi Gas dan Triplesat Log untuk mencari Minyak dan Gas.
Aplikasi Pulse Neutron Logging untuk Menentukan Zona Hidrokarbon Baru di Lapangan X HASIL DAN PEMBAHASAN

Tujuan utama dari alat Reservoir Monitoring Tool (RMTI) adalah untuk mengidentifikasi sisa potensi hidrokarbon di belakang casing, menentukan jenis fluida dan tekanan reservoir sebelum mendapatkan update data reservoir untuk evaluasi kandidat untuk workover (Jerome, 2010).

\section{Diagram Alir Pekerjaan Interpretasi Hasil Rekaman \\ Pulse Neutron adalah alat untuk} mengukur kadar Carbon di minyak dan Oksigen di air. Ketika alat ini menangkap air maka kadar atom $\mathrm{O}$ akan tinggi dan atom $\mathrm{C}$ rendah. Apabila alat ini menangkap Hidrocarbon maka atom $\mathrm{C}$ akan tinggi dan atom $\mathrm{O}$ akan rendah. Rasio dari Carbon dan Oksigen tersaji antara air dan Hidrocarbon tergantung dari salinitas air. Pada proses $C / O$ kali ini di khususkan hanya untuk mencari Minyak (Gingger, 2005).

Di bawah ini adalah diagram alir dari Procesing Carbon Oksigen itu rangkaian casing yang direncanakan pada suatu lapangan harus mampu menahan beban-beban yang terjadi, seperti halnya : Beban Burst, Beban Collapse dan Beban Tension. Selain mampu menahan beban-beban diatas, yang perlu diperhatikan juga adalah ketahanan casing terhadap kondisi lubang di lapangan yang mempunyai karakteristik khusus Sigma adalah salah satu proses interpretasi dalam menetukan minyak dari dalam formasi.

Dengan proses Sigma Log ini kita dapat membedakan antara air asin dan minyak, vapor dan air, minyak dan vapor. Vapor disini adalah terdiri dari Methane, carbondioksida, nitrogren dan steam. Di bawah ini adalah diagram alir dari Procesing Carbon Oksigen (De Coaster, 2005).

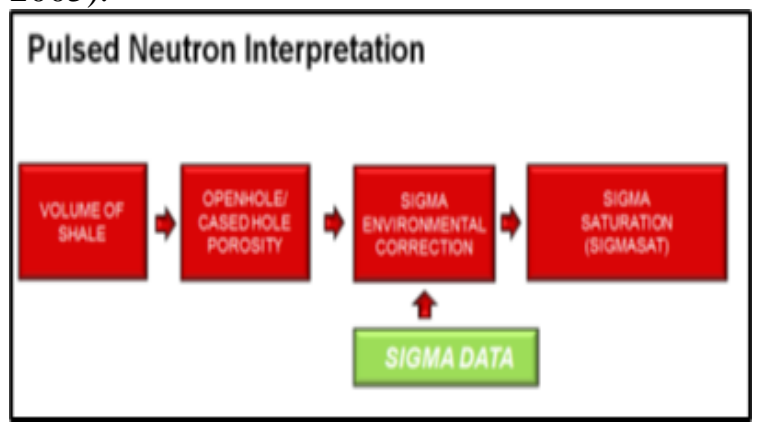

Gambar 2 Flow Diagram Proses C/O 


\section{Hasil Interpretasi Cased Hole Logging}

Setelah melalui proses diharapkan data yang telah dihasilkan adalah data yang telah melalui beberapa tahapan koreksi. Koreksi kali ini digunakan agar untuk meminimalisir kesalahan-kesalahan pada pembacaan alat karena terlalu banyak gangguan di dalam sumur. Pada interpretasi ini terdapat dua model yaitu Sigma Log dan C/O Log. Sigma Log di gunakan untuk mencari gas dan $\mathrm{C} / \mathrm{O} \mathrm{Log}$ tujuannya adalah untuk mencari minyak (Weijunm, 2010)

\section{Informasi Data Sumur}

RMTI adalah alat untuk mengevaluasi gas dan potensi minyak di dalam. Sumur $\mathrm{X}$ terletak di daerah Jawa timur.

RMTI (Sigma Mode dan C/O Mode) telah di aplikasikan pada sumur $\mathrm{X}$ pada tanggal 28 Nov 2014. Pada RMTI ini di jalankan pada inside 4.5" liner dan pada interval 7860-7650 FT MD (Gambar. 3). Untuk RMTI Sigma mode yang di jalankan pada 7" dan 4.5" liner dan pada interval 7850-5600 (Gambar. 3). Tetapi untuk processing hanya pada interval 6000-5640 FT.

Environmental Correction telah di lakukan untuk RMTI yang meliputi:

1. Ukuran casing

2. Ketebalan casing

3. Bit size

4. Litologi

5. Salinitas air di dalam casing

Pada Sigmasat Modul dipergunakan untuk memperoleh harga gas dengan perhitungan Sigma Intrinsic dan Carboxsat modul tujuannya untuk mendapatkan saturasi minyak dengan perhitungan rasio $\mathrm{C} / \mathrm{O} \mathrm{Log}$ (Salim, 200\&).

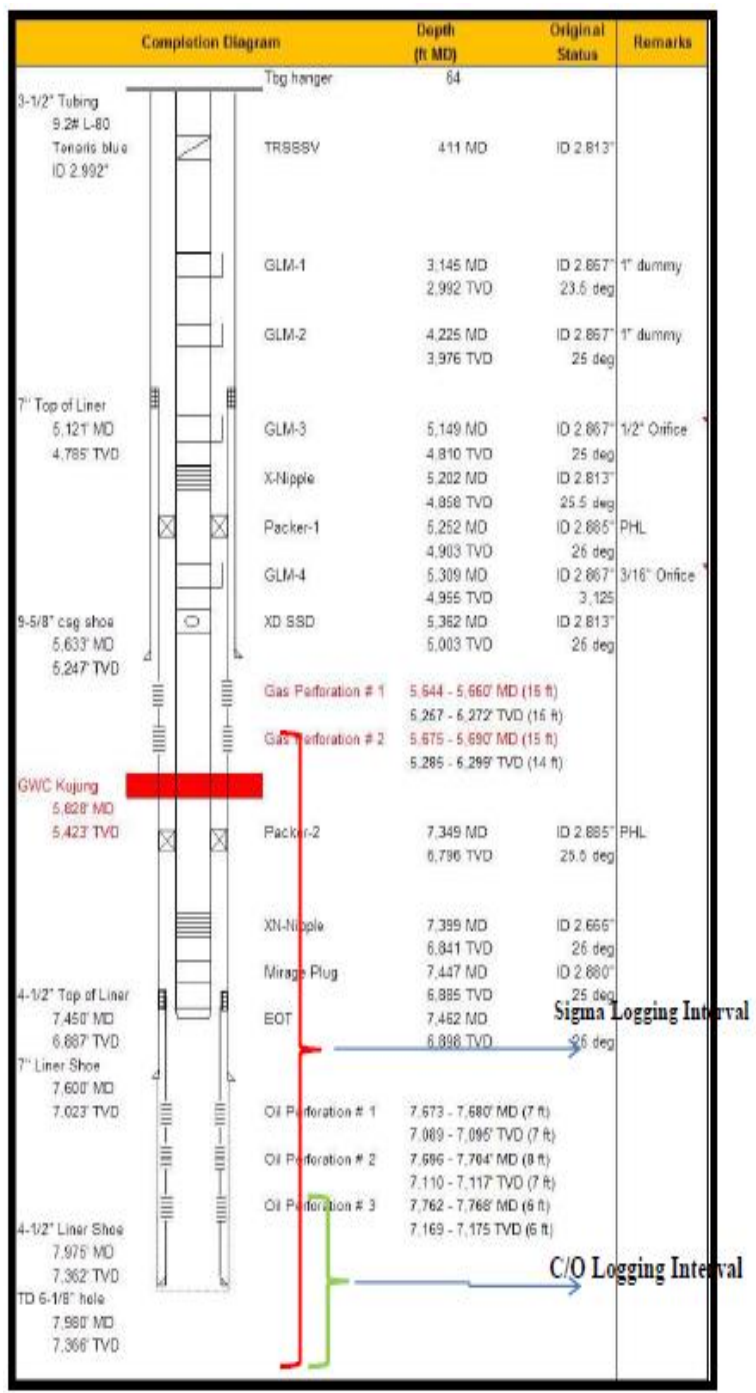

Gambar 3 Well Diagram

\section{Interpretasi Kualitas Data Log}

Seluruh data akan melalui beberapa RMTI prosesing model untuk energi Gain Stabilization windows dan enviromental correction tujuan meminimalisir dari efek lubang sumur dan alat-alat yang berada di dalam sumur yang mungkin akan mempengaruhi efek dari hasil Log Sigma Log dan C/O Log. Sebelum mengerjakan data RMTI terlebih dahulu melalui tahap yaitu data tersebut di siapkan terlebih dahulu. Pada sub bab di bawah akan di bahas tentang preparasi data. 


\section{Preparasi Data Sigma Log}

Dibawah ini adalah langkah-langkah untuk persiapan data untuk sigma

1. Langkah 1. Gain Stabilization (Relog for spectra) (Microsoft, 2007).

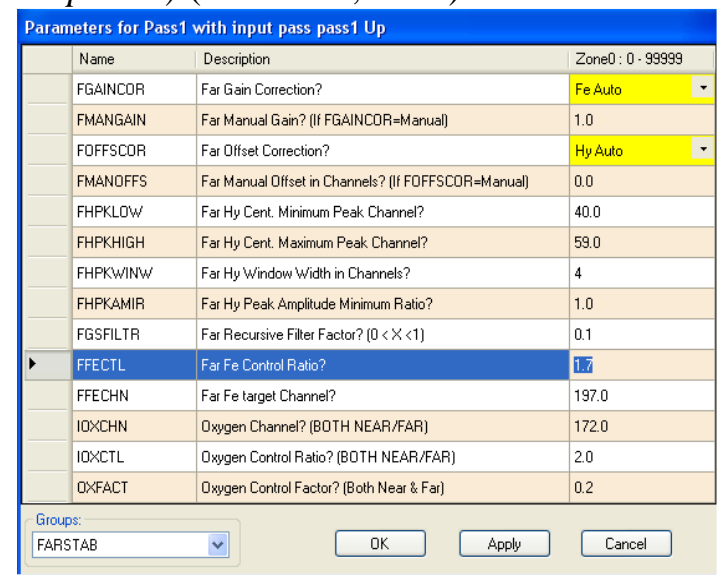

Gambar 4 Input parameter untuk Far Detector (Microsoft, 2007)

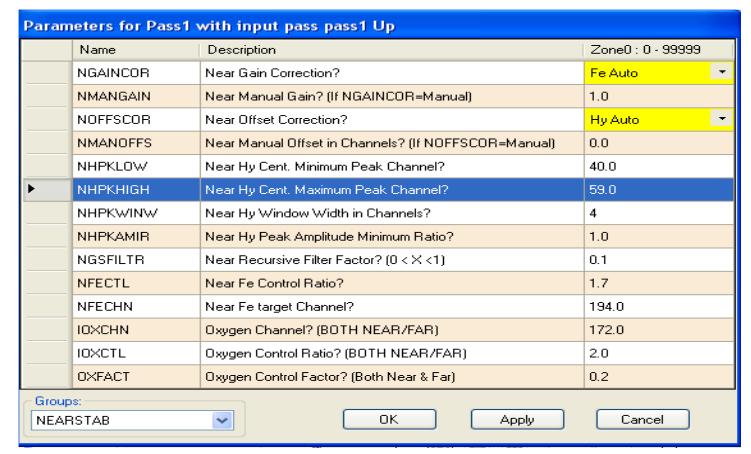

Gambar 5 Input parameter untuk Near Detector (Microsoft, 2007)

Setelah masuk kan Far Parameter (Gambar 3) dan Near Parameter Gambar 5) lalu akan mendapatkan seperti Log di bawah (Gambar 6). Pada proses di atas bertujuan untuk menyelaraskan puncak pada kurva spektrum antara Far dan Near. Apabila belum mendapatkan hasil yang bagus pada log bisa kembali mengubah beberapa pada Far dan Near Parameter.
Aplikasi Pulse Neutron Logging untuk Menentukan Zona Hidrokarbon Baru di Lapangan X

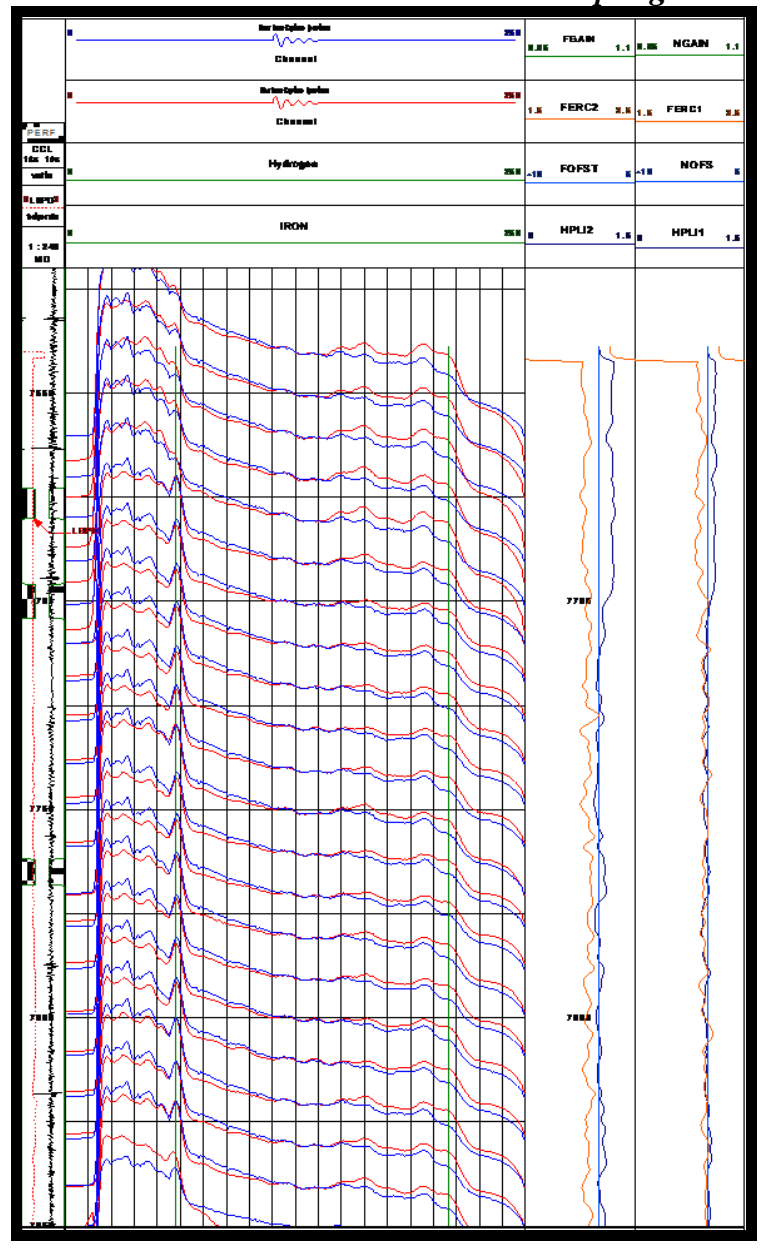

Gambar 6 Log untuk Gain Stabilization

2. Langkah 2. Enviromental Corection

Pada Environmental Correction dapat memasukkan data dari Vshale dan Total Porositas. Pada Gambar 7 adalah tabel untuk

memasukkan parameter Vshale. Pada Gambar. 8 adalah tabel untuk memasukan parameter Total Porositas. Koreksi Sigma di aplikasikan untuk mengoreksi terhadap data RMTI.

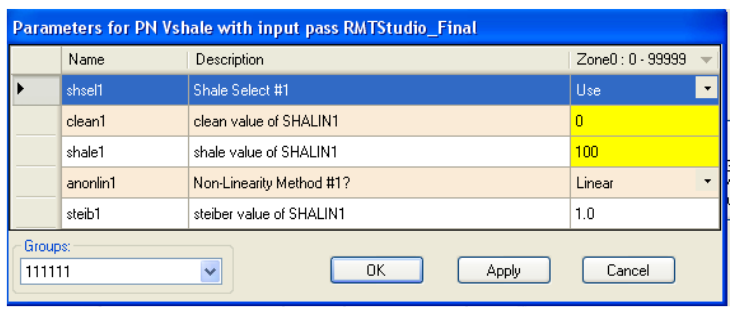

Gambar 7 Input parameter untuk Vshale (Microsoft, 2007) 


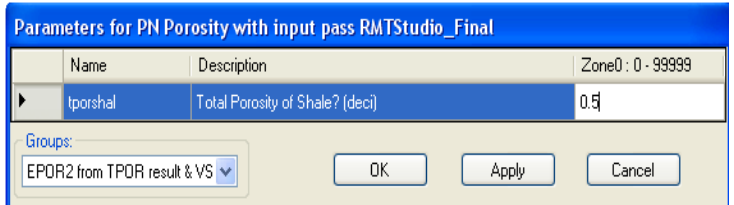

Gambar 8 Input parameter untuk Total porosity (Microsoft, 2007)

\section{Preparasi Data C/O Log}

Environmental Corection pada $\mathrm{C} / \mathrm{O}$ digunakan untuk mengkoreksi data $C / O$ terhadap Borehole size, casing/tubing size dan borehole salinity. Salinitas pada sumur dikoreksi sebesar $5000 \mathrm{ppm} \mathrm{NaCl}$. Data $C / O$ telah di koreksi dengan oil column di casing dan tubing. Berikut ini adalah langkah-langkah persiapan data untuk $C / O$.

1. Langkah-1. Gain Stabilization (penjelasan pada preparasi data Sigma)

2. Langkah-2. Average spectra from multi passes

Berbeda dari preparasi data Sigma, untuk data $C / O$ ada satu bagian yang di tambahkan yaitu Average Spectra. Pada tahapan ini akan mengumpulkan 3 buah pass data untuk menjadi 1 buah data pass. Pass data adalah ketika alat mulai merekam dari top depth sampai ke bottom depth dan kembali lagi ke top depth itu lah yg di sebut 1 buah data pass.

Tujuan tahapan ini adalah untuk melihat data rata-rata dari setiap pass. Pada Gambar. 8 dan Gambar. 9 adalah tabel untuk memasuk kan beberapa parameter. Hasil dari Average Spectra seperti terlihat pada Gambar 11.

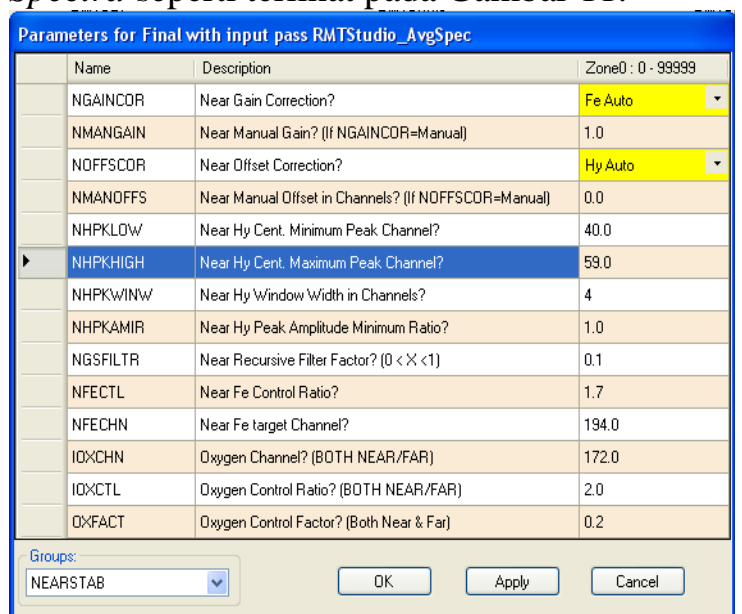

Gambar 9 Input Near Parameter untuk Log Average (Microsoft, 2007)

\begin{tabular}{|c|c|c|c|}
\hline \multicolumn{4}{|c|}{ Parameters for Final with input pass RMTStudio_AvgSpec } \\
\hline & Name & Description & Zone0: 0.99999 \\
\hline & FGAINCOR & Far Gain Correction? & Fe Auto \\
\hline & FMANGAIN & Far Manual Gain? (If FGAINCOR=Manual) & 1.0 \\
\hline & FOFFSCOR & Far Offset Correction? & Hy Auto \\
\hline & FMANOFFS & Far Manual Offset in Channels? (If FOFFSCOR=Manual) & 0.0 \\
\hline & FHPKLOW & Far Hy Cent. Minimum Peak Channel? & 40.0 \\
\hline & FHPKHIGH & Far Hy Cent. Maximum Peak Channel? & 59.0 \\
\hline - & FHPKWINW & Far Hy Window Width in Channels? & 4 \\
\hline & FHPKAMIR & Far Hy Peak Amplitude Minimum Ratio? & 1.0 \\
\hline & FGSFILTR & Far Recursive Filter Factor? $[0<X<1)$ & 0.1 \\
\hline & FFECTL & Far Fe Control Ratio? & 1.7 \\
\hline & FFECHN & Far Fe target Channel? & 197.0 \\
\hline & IOXCHN & Oxygen Channel? (BOTH NEAR/FAR) & 172.0 \\
\hline & IOXCTL & Oxygen Control Ratio? (BOTH NEAR/FAR) & 2.0 \\
\hline & OXFACT & Oxygen Control Factor? (Both Near \& Far) & 0.2 \\
\hline \multicolumn{3}{|c|}{ Groups: } & \\
\hline & & Apply & Cancel \\
\hline
\end{tabular}

Gambar 10 Input Far Parameter untuk Log Average (Microsoft, 2007)

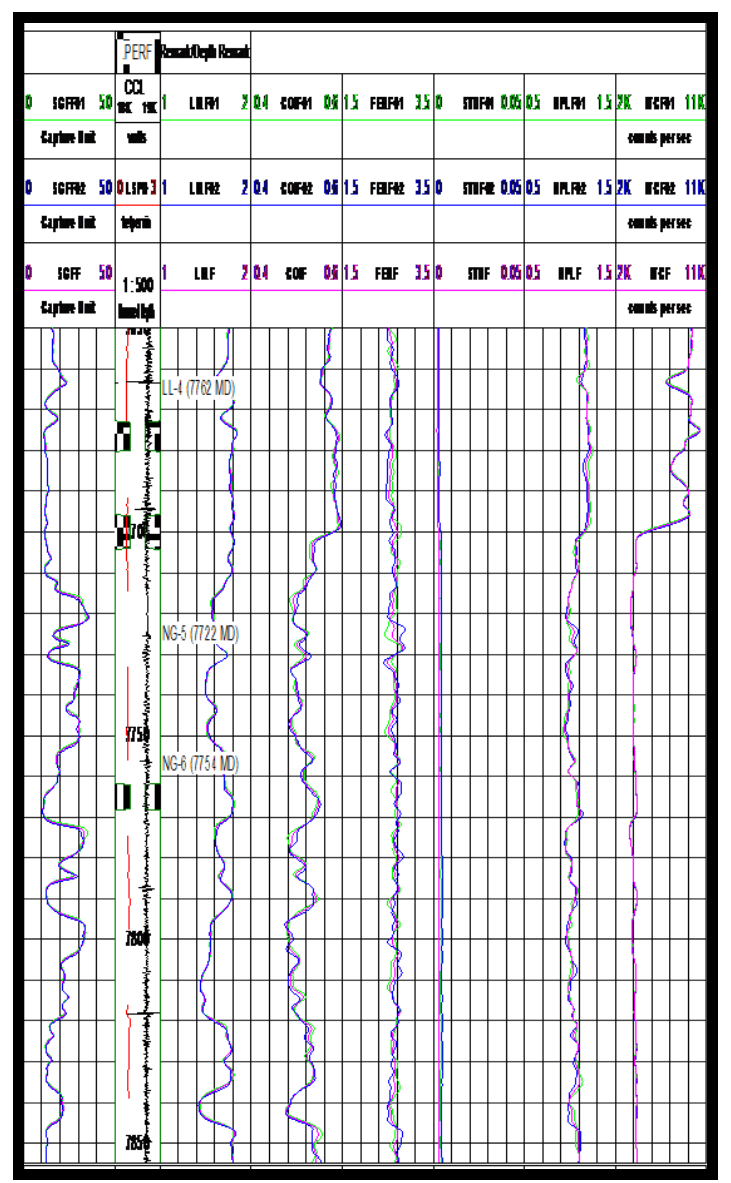

Gambar 11 Log Average untuk C/O3.

3. Langkah-3. $C / O$ mode Environmental Corection (penjelasan pada preparasi data Sigma) 


\section{Model Interpretasi}

Setelah melalui proses diatas diharapkan data yang telah dihasilkan adalah data yang telah melalui beberapa tahapan koreksi. Koreksi kali ini digunakan agar untuk meminimalisir kesalahan-kesalahan pada pembacaan alat karena terlalu banyak gangguan di dalam sumur. Pada interpretasi ini terdapat dua model yaitu sigma Log dan $C / O$ Log. Sigma Log di gunakan untuk mencari gas dan $C / O$ Log tujuannya adalah untuk mencari minyak (Weijun, 2011).

\section{Sigma Saturation (Sigmasat)}

Sigma Saturation (SigmaSat) adalah salah satu modul interpretasi Pulse Neutron dimana digunakan untuk mengkalkulasi saturasi dari sigma. Pada modul Sigma Saturation para meter yang digunakan adalah:

1. $\Sigma$ water $=32 \mathrm{Cu}$, berdasarkan formation water salinity: $6 \mathrm{Kppm}$.

2. $\Sigma$ gas $=3 \mathrm{Cu}$, berdasarkan temperature dan pressure.

3. $\Sigma$ shale $=12 \mathrm{Cu}$, berdasarkan sigma intrinsic value di shale zone.

4. Lmatrix $=8 \mathrm{Cu}$, berdasarkan sigma apparent matrix value di clean water zone (Asquith, 2005).

\section{Carbon Oksigen Saturation (CarbOxsat)}

Saturasi Hidrocarbon (minyak) yang di komputasi dengan menggunakan CarbOxsat Saturation model dari stacking data, penggabungan data dan rata-rata antara 3 RMTI $C / O$ mode dari setiap pass nya dan dari data open hole.

Seluruh data akan melalui beberapa RMTI prosesing model untuk energi Gain Stabilization windows dan enviromental correction untuk meminimalisir dari efek lubang sumur dan alat-alat yang berada di dalam sumur yang mungkin akan mempengaruhi efek dari perhitungan.

Volume Shale dan porositas adalah dasar utama dalam mengerjakan model ini, yaitu dengan memasukkan Vshale dan Porositas yang diberikan dari customer yang berasal dari perhitungan Open hole Log (Gingger, 2005).

\section{Hasil Prosesing Cased Hole Logging}

Pada Pembahasan kali ini penulis ingin menjelaskan tentang hasil dari prosesing Sigma Saturation (SigmaSat) dan Carbon Oksigen Saturation (CarboxSat). Sigma Saturation modul di peruntukkan untuk mengkalkulasi
Aplikasi Pulse Neutron Logging untuk Menentukan Zona Hidrokarbon Baru di Lapangan X gas dari sigma intrinsic. Sedangkan Carbon Oksigen Saturation (CarboxSat) di gunakan untuk mengetahui saturasi minyak di dalam sumur.

\section{Sigma Saturation}

Modul Sigma Saturasi digunakan untuk mengkalkulasi saturasi gas dan sigma intrinsic. Pada Gambar 12 adalah hasil dari Sigma Saturasi Analisis dari sumur ini.

Semua data telah di depth correlated dengan data Open Hole. Porositas telah di kalkulasi dari xplot density dan neutron porosity

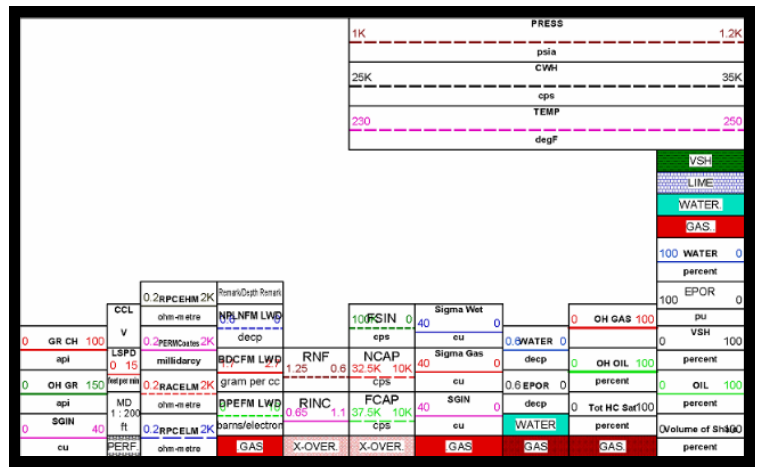

Gambar 12 Kepala Log dari Sigma Saturation

\section{Hasil Prosesing Cased Hole Logging}

Pada Pembahasan kali ini penulis ingin menjelaskan tentang hasil dari prosesing Sigma Saturation (SigmaSat) dan Carbon Oksigen Saturation (CarboxSat). Sigma Saturation modul di peruntukkan untuk mengkalkulasi gas dari sigma intrinsic. Sedangkan Carbon Oksigen Saturation (CarboxSat) di gunakan untuk mengetahui saturasi minyak di dalam sumur.

\section{Sigma Saturation}

Modul Sigma Saturasi digunakan untuk mengkalkulasi saturasi gas dan sigma intrinsic. Pada Gambar 13 adalah hasil dari Sigma Saturasi Analisis dari sumur ini.

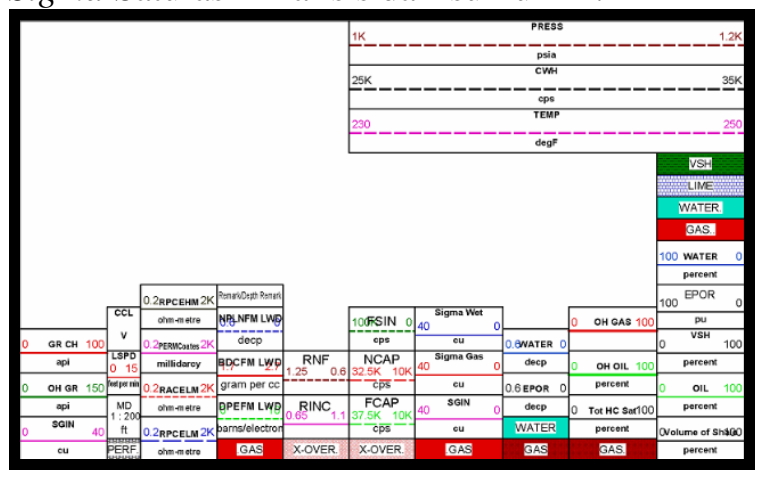

Gambar 13. Kepala Log dari Sigma Saturation 
Submitted: 08/10/2020; Revised: 21/10/2020; Accepted: 28/10/2020; Published: 30/10/2020

Semua data telah di depth correlated dengan data Open Hole. Porositas telah di kalkulasi dari xplot density dan neutron porosity

Gambar 13

Legenda :

1. Track 1:

GR_OH adalah open hole gamma ray.

GR_CH adalah cased hole gamma ray.

SGIN adalah Sigma Intrinsic.

Track Depth:

LSPD adalah wireline line speed (ft/min).

CCL adalah

2. Track 2:

RACELM adalah $L W D$ deep resistivity. RPCLM adalah $L W D$ shallow resistivity RPCEHM adalah LWD invaded zone resistivity

PERMCoates adalah Coates permeability value

3. Track 3:

BDCFM (Bulk Density) adalah LWD bulk density

NPLNFM (Neutron Porosity) adalah LWD neutron porosity (Limestone matrix).

DPEFM (Photo Electric) adalah LWD PE

4. Track 4:

RINC (Corrected Inelastic Ratio) adalah koreksi dari inelastic ratio (near/far) dimana seperti pseudo density untuk open hole data.

RNF (Ratio Near/Far) adalah ratio near dan far capture count rate dari RMTI, seperti pseudo neutron porosity dari open hole data.

5. Track 5:

FCAP (Far capture counts) adalah capture counts rate dari far detector.

NCAP (Near capture counts) adalah capture counts rate dari near detector.

FSIN (Far inelastic count rate) adalah inelastic count rate dari far detector 67

6. Track 6:

Sigma Wet adalah angka sigma dimana $100 \%$ air di formasi

Sigma Gas adalah adalah angka sigma dimana $100 \%$ Gas di formasi

SGIN (Sigma Intrinsic) adalah sigma intrinsic

7. Track 7:

Water (VWEFF) adalah volume air di effective porosity.

EPOR adalah effective porosity yang di dapat dari Customer
8. Track 8:

Tot HC Sat HC/Gas saturation dari SigmaSat ${ }^{\mathrm{TM}}$

SWE_Client HC/Gas saturation dari Customer

9. Track 9:

EPOR adalah effective porosity yang di dapat dari Customer

Water (VWEFF) adalah volume dari air di effective porosity.

VSH adalah volume dari shale yang di peroleh dari customer

10. Track 10:

PRESS adalah pressure di borehole

CWH (capacitance water hold up) adalah capacitance fluid di borehole

TEMP adalah temperatur di borehole

\section{Carbon Oksigen Saturation}

Modul Sigma Saturasi digunakan untuk mengkalkulasi saturasi minyak. Pada Gambar 14 adalah hasil dari Sigma Saturasi Analisis dari sumur ini. Semua data telah di depth correlated dengan data Open Hole. Porositas telah di kalkulasi dari xplot density dan neutron porosity

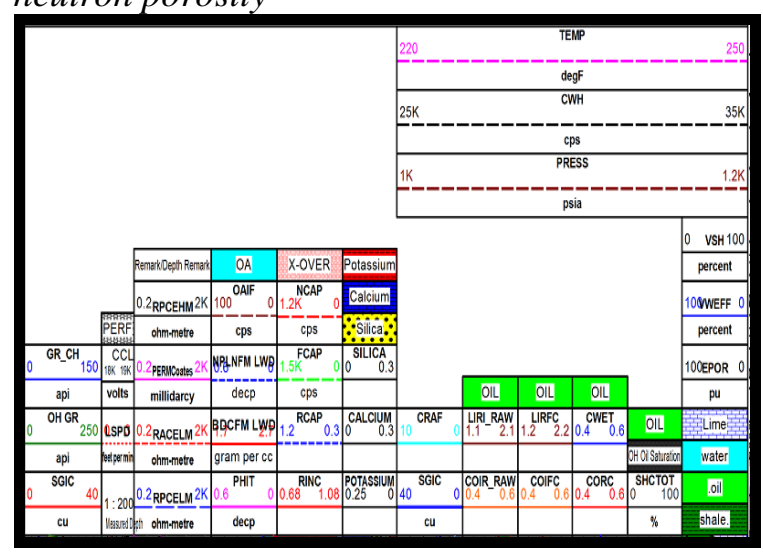

Gambar 14 Kepala Log dari Carbon Oksigen Saturation

Legenda:

1. Track 1:

GR_OH adalah open hole gamma ray.

GR_CH adalah cased hole gamma ray

SGIN adalah Sigma Intrinsic.

Track Depth:

LSPD adalah wireline line speed (ft/min).

CCL adalah casing collar locator.

2. Track 2:

RACELM adalah $L W D$ deep resistivity.

RPCLM adalah $L W D$ shallow resistivity

RPCEHM adalah LWD invaded zone

resistivity

PERMCoates adalah Coates permeability 
3. Track 3:

BDCFM (Bulk Density) adalah LWD bulk density

NPLNFM (Neutron Porosity) adalah LWD neutron porosity (Limestone matrix).

OAIF adalah oxygen activation indicator dari far detector.

4. Track 4:

NCAP (Near capture counts) adalah capture counts rate dari near detector.

FCAP (Far capture counts) adalah capture counts rate dari far detector.

RCAP(Ratio near/far capture) adalah near to far capture counts rate ratio

RINC (Ratio near/far inelastic corrected) RCAP adalah RINC kurva yang akan di overlay di wet atau zona shale. Biasanya FCAP lebih besar dari pada NCAP, ini membuktikan bahwa adanya gas bearing atau zona tight

5. Track 5:

SILICA (YSI) adalah Silicon Yield

CALCIUM (YCa) adalah Calcium Yield

POTASSIUM (YK) adalah Potassium Yield

6. Track 6:

CRAF adalah compton ratio far

SGIC (Sigma Intrinsic) adalah sigma intrinsic

7. Track 7:

LIRI_RAW adalah Calcium/Silicon inelastic ratio far detector setelah gain stabilization

COIR_RAW adalah Carbon/Oxygen inelastic ratio far detector setelah gain stabilization

8. Track 8:

LIRFC adalah Calcium/Silicon inelastic ratio far detector corrected dari well completion dan environment

COIFC adalah Carbon/Oxygen inelastic ratio far detector corrected dari well completion dan environment

9. Track 9:

CWET adalah Carbon/Oxygen di wet formation

CORC adalah Carbon/Oxygen inelastic ratio far detector corrected dari sumur completion and environment (These two curves are stacked in wet zone (water zone))

10. Track 10:

Tot HC Sat adalah HC/Gas saturation calculated dari CarboxSat ${ }^{\mathrm{TM}}$ processing

SWE_Client HC/Gas saturasi dari Customer
Aplikasi Pulse Neutron Logging untuk Menentukan Zona Hidrokarbon Baru di Lapangan $X$

11.Track 11:

EPOR adalah effective porosity diperoleh dari customer

Water (VWEFF) adalah volume air dari effective porosity.

VSH adalah volume of shale diperoleh dari customer

12.Track 12:

PRESS adalah pressure in the borehole

CWH (capacitance water hold up) adalah capacitance fluid di borehole

TEMP adalah temperatur di borehole

\section{KESIMPULAN DAN SARAN}

Kesimpulan yang diperoleh yaitu RMTi bekerja baik pada capture mode dan co mode. Terdapat fluida berbeda di dalam Borehole SigmaSat prosesing memberikan formasi gas saturation dengan menggunakan Sigma Intrinsic dan Open Hole Logs. CarboxSat prosesing memberikan Saturasi Minyak dengan menggunakan $\mathrm{CO}$ rasio dan Open Hole $\log$

\section{DAFTAR PUSTAKA}

Analysts Journal, SPWLA 51 $1^{\text {st }}$ Annual Logging Symposium, 19-23 June, SPWLA-2010-48800.

Asquith, G., \& Gibson, C. (2005). Basic Well Log Analysis for Geologists. The American Association of Petroleum Geologists, Tulsa, Oklahoma, USA.

De Coaster, G. L. (2005). The Geology of the Java Basin. Procced 3rd Ann. Conv IPA 3-4/6/2005: Jakarta, p 77-110

Eko, P. (2010). Pulse Neutron Process and Aplication (Internal Study) . Jakarta: Ubhara Jaya.

Gingger, D. \& Fielding, K. (2005). Petroleum System and Future Potential of South Sumatra Basin. Procced 30th Ann. Conv IPA 2005: Jakarta.

Harsono, A. (2006). Evaluasi Formasi dan Aplikasi Log, Edisi-8. Schlumberger Oilfield Services, Kuningan, Jakarta, Indonesia

Guo,W., Dorffer, D., \& Kwong, S. (2011). Cased-Hole Porosity Measurements Using Pulsed Neutron Logging Tools. Society of Petrophysicists and Well log Analysts Journal, SPWLA $51^{\text {st }}$ Annual Logging Symposium, 19-23 June, SPWLA-2010-48800. 
Eko Prastio, ST, MT

Submitted: 08/10/2020; Revised: 21/10/2020; Accepted: 28/10/2020; Published: 30/10/2020

Guo, W., Jacobson, L., Truax, J., Dorffer, D., \& Kwong, S. (2010). A New Threedetector 1-11/16 Inch Pulsed Neutron Tool For Unconventional Reservoirs. Society of Petrophysicists and Well log Analysts Journal, SPWLA 51 $1^{\text {st }}$ Annual Logging Symposium, 19-23 June, SPWLA-2010-48800.

Microsoft. (2017). INSITE Software User's Manual version 4.x for Windows, Inc. Windows.

Truax, J., Dorffer, D., \& Kwong, S. (2010). Pulsed Neutron Tool For Unconventional Resevoirs. Society of Petrophysicists and Well log Analysts Journal, SPWLA 51 $1^{\text {st }}$ Annual Logging Symposium, 19-23 June, SPWLA-201048800.

Salim, Y., et al. (2007). Remaining Potential of The Java Basin Study Report. South Sumatra AMI Study Group: Santa Fe Energy Resources S.E. Asia Limited, Anadarko Petroleum Corp., KerrMcGee Corp. 